NASA/TM-2012-217295

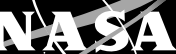

Current Status of Superheat Spray Modeling With NCC

M.S. Raju

ASRC Aerospace Corporation, Cleveland, Ohio

Dan L. Bulzan

Glenn Research Center, Cleveland, Ohio 


\section{NASA STI Program . . . in Profile}

Since its founding, NASA has been dedicated to the advancement of aeronautics and space science. The NASA Scientific and Technical Information (STI) program plays a key part in helping NASA maintain this important role.

The NASA STI Program operates under the auspices of the Agency Chief Information Officer. It collects, organizes, provides for archiving, and disseminates NASA's STI. The NASA STI program provides access to the NASA Aeronautics and Space Database and its public interface, the NASA Technical Reports Server, thus providing one of the largest collections of aeronautical and space science STI in the world. Results are published in both non-NASA channels and by NASA in the NASA STI Report Series, which includes the following report types:

- TECHNICAL PUBLICATION. Reports of completed research or a major significant phase of research that present the results of NASA programs and include extensive data or theoretical analysis. Includes compilations of significant scientific and technical data and information deemed to be of continuing reference value. NASA counterpart of peer-reviewed formal professional papers but has less stringent limitations on manuscript length and extent of graphic presentations.

- TECHNICAL MEMORANDUM. Scientific and technical findings that are preliminary or of specialized interest, e.g., quick release reports, working papers, and bibliographies that contain minimal annotation. Does not contain extensive analysis.

- CONTRACTOR REPORT. Scientific and technical findings by NASA-sponsored contractors and grantees.
- CONFERENCE PUBLICATION. Collected papers from scientific and technical conferences, symposia, seminars, or other meetings sponsored or cosponsored by NASA.

- SPECIAL PUBLICATION. Scientific, technical, or historical information from NASA programs, projects, and missions, often concerned with subjects having substantial public interest.

- TECHNICAL TRANSLATION. Englishlanguage translations of foreign scientific and technical material pertinent to NASA's mission.

Specialized services also include creating custom thesauri, building customized databases, organizing and publishing research results.

For more information about the NASA STI program, see the following:

- Access the NASA STI program home page at http://www.sti.nasa.gov

- E-mail your question via the Internet to help@ sti.nasa.gov

- Fax your question to the NASA STI Help Desk at $443-757-5803$

- Telephone the NASA STI Help Desk at 443-757-5802

- Write to: NASA Center for AeroSpace Information (CASI) 7115 Standard Drive Hanover, MD 21076-1320 
NASA/TM-2012-217295

NESEA

Current Status of Superheat Spray Modeling With NCC

M.S. Raju

ASRC Aerospace Corporation, Cleveland, Ohio

Dan L. Bulzan

Glenn Research Center, Cleveland, Ohio

Prepared for the

48th Joint Propulsion Conference and Exhibit

cosponsored by AIAA, ASME, SAE, and ASEE

Atlanta, Georgia, July 30-August 1, 2012

National Aeronautics and

Space Administration

Glenn Research Center

Cleveland, Ohio 44135 


\section{Acknowledgments}

This work was supported by the supersonics (SUP) project office of the NASA Fundamental Aeronautics Program with Dr. N.-S. Liu acting as the technical monitor. The authors would like to extend their sincere appreciation to

Dr. Jeff Moder for his many valuable contributions to the spray code.

Trade names and trademarks are used in this report for identification only. Their usage does not constitute an official endorsement, either expressed or implied, by the National Aeronautics and Space Administration.

This work was sponsored by the Fundamental Aeronautics Program at the NASA Glenn Research Center.

Level of Review: This material has been technically reviewed by technical management.

Available from

NASA Center for Aerospace Information 7115 Standard Drive

Hanover, MD 21076-1320
National Technical Information Service 5301 Shawnee Road Alexandria, VA 22312 


\title{
Current Status of Superheat Spray Modeling With NCC
}

\author{
M.S. Raju \\ ASRC Aerospace Corporation \\ Cleveland, Ohio 44135 \\ Dan L. Bulzan \\ National Aeronautics and Space Administration \\ Glenn Research Center \\ Cleveland, Ohio 44135
}

\begin{abstract}
An understanding of fuel atomization and vaporization behavior at superheat conditions is identified to be a topic of importance in the design of modern supersonic engines. As a part of the NASA's fundamental aeronautics program (the supersonics (SUP) project office initiative on high altitude emissions), we have undertaken an effort to assess the accuracy of various existing CFD models used in the modeling of superheated sprays. As a part of this investigation, we have completed the implementation of a solution procedure for the modeling of superheated sprays into the national combustion code (NCC), and then applied it to investigate the following three cases: (1) the validation of a flashing jet generated by the sudden release of pressurized R134A from a cylindrical nozzle, (2) the differences between two superheat vaporization models were studied based on the predicted results of both hot and cold flow calculations involving a Parker-Hannifin pressure swirl atomizer, (3) the spray characteristics generated by a single-element LDI (Lean Direct Injector) combustion experiment were studied to investigate the differences between superheat and non-superheat conditions. For the validation case, the predicted results provided reasonable agreement for both gas and droplet velocities but underpredicted the droplet sizes by a considerable measure in the central region. For the second case, the superheat vaporization models of both [12-14] and [15] produced similar results for a hot flow. For the third case, both the superheat and non-superheat calculations produced mostly similar results for gas temperature and velocities but the su-
\end{abstract}

perheat calculation produced substantially faster vaporization as expected.

\section{NOMENCLATURE}

\begin{tabular}{|c|c|}
\hline$B_{k}$ & Spalding mass transfer number \\
\hline$B_{t}$ & Spalding heat transfer number \\
\hline$C_{p}$ & specific heat, $\mathrm{J} /(\mathrm{kg} \mathrm{K})$ \\
\hline$d$ & droplet diameter, $\mathrm{m}$ \\
\hline$d t$ & time increment, $\mathrm{s}$ \\
\hline$h$ & specific enthalpy, $\mathrm{J} / \mathrm{kg}$ \\
\hline$k$ & thermal conductivity, $\mathrm{J} /(\mathrm{ms} \mathrm{K})$ \\
\hline$l_{k}$ & mixture latent heat of evaporation, $\mathrm{J} / \mathrm{kg}$ \\
\hline$l_{k, e f f}$ & $\begin{array}{l}\text { effective latent heat of evaporation, } \\
\mathrm{J} / \mathrm{kg} \text { (defined in Eq. (14)) }\end{array}$ \\
\hline$\dot{m}$ & liquid mass flow rate, $\mathrm{kg} / \mathrm{s}$ \\
\hline$\dot{m}_{k, \text { flash }}$ & $\begin{array}{l}\text { droplet vaporization rate under } \\
\text { flash evaporating conditions, } \mathrm{kg} / \mathrm{s}\end{array}$ \\
\hline$\dot{m}_{k, t}$ & $\begin{array}{l}\text { droplet vaporization rate due } \\
\text { to heat transfer, } \mathrm{kg} / \mathrm{s}\end{array}$ \\
\hline$n_{k}$ & number of droplets in kth group \\
\hline$N u$ & Nusselt number \\
\hline$P$ & pressure, $\mathrm{N} / \mathrm{m}^{2}$ \\
\hline $\operatorname{Pr}$ & Prandtl number \\
\hline$P_{\text {sat }}$ & saturation pressure, $\mathrm{N} / \mathrm{m}^{2}$ \\
\hline$r_{k}$ & droplet radius, $\mathrm{m}$ \\
\hline$R_{u}$ & gas constant, $\mathrm{J} /(\mathrm{kg} \mathrm{K})$ \\
\hline$R e$ & Reynolds number \\
\hline$S h$ & Sherwood number \\
\hline$s_{k}$ & droplet radius-squared $\left(=\mathrm{r}_{k}^{2}\right), \mathrm{m}^{2}$ \\
\hline$S c$ & Schmidt number \\
\hline$S M D$ & Sauter mean diameter, m \\
\hline$t$ & time, $\mathrm{s}$ \\
\hline$T$ & temperature, $\mathrm{K}$ \\
\hline
\end{tabular}




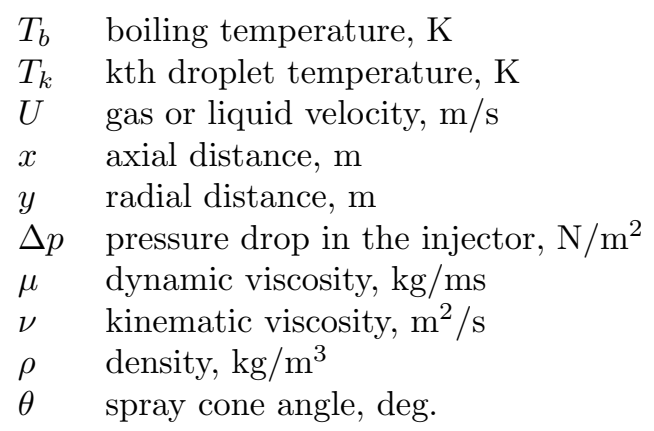

\section{Subscripts}

$\begin{array}{ll}f & \text { fuel } \\ g & \text { gas } \\ i n j & \text { injector } \\ l & \text { liquid } \\ r & \text { radial coordinate } \\ s & \text { droplet surface } \\ t & \text { time } \\ x & \text { axial or x-coordinate } \\ y & \text { y-coordinate } \\ z & \text { z-coordinate }\end{array}$

\section{Superscripts}

mean, or average

flow rate

\section{INTRODUCTION}

Our previous work on spray modeling can be found in Refs. [1-10]. The spray solution procedure facilitates multi-dimensional spray/gaseous combustion calculations on massively parallel computers and unstructured grids. It also allows calculations to be performed in conjunction with the scalar Monte Carlo PDF (Probability Density Function) method [2]. The objective of our present study is to extend our solution procedure to the modeling of superheated sprays because of its importance in the design of modern supersonic engines, scramjet, and ramjet afterburners [11-15]. It is because higher heat-load requirements may lead to the use of the the same fuel as a coolant and also sometimes the nozzles are required to operate at low back pressures. Also, under normal gasturbine operating conditions, it is estimated that a small fraction of the liquid fuel may be flash boiled [12]. There are also some reported cases of flash related engine performance problems in gasoline directinjection internal combustion engines [12]. Although flash evaporation is considered to be detrimental to engine performance under normal circumstances, it can have some potential benefits: it is known to produce a fine spray with enhanced atomization, increase effective spray cone angle, and decrease spray penetration [11]. Because of its importance in some NASA-related applications, we have undertaken an assessment study to establish baseline accuracy of various existing CFD models used in the modeling of a superheated spray. As a part of this effort, we have implemented a solution procedure into NCC based on the modeling approach developed by [12-15]. More specifically, we have implemented a superheat vaporization model and other modifications pertinent to the atomization modeling developed by [12-14]. Also, we have completed the integration of a computer module that was developed by UTRC (United Technologies Research Center) and UMASS (University of Massachusetts) [15]. The UTRC/UMASS computer module contained a separate superheat vaporization model, a flash-induced atomization breakup-model, and a calculation approach that was developed to determine the JP8 two-phase properties [15]. In order to establish a baseline accuracy of the solution procedure, we have undertaken a validation involving a flashing jet generated by a cylindrical nozzle [16]. Also, we have performed some calculations involving a Parker-Hannifin pressure swirl atomizer in order to evaluate the differences between the superheat vaporization models of [12-14] and [15], and a single element LDI reacting case in order to evaluate the differences between the superheat and non-superheat conditions [16].

In this paper, we first describe complete details of the solution procedure implemented into NCC followed by a presentation of the results.

\section{ATOMIZATION MODELING}

The atomization refers to a process of the liquid jet breakup into droplets. There are many processes associated with the liquid jet breakup. They can broadly be classified into two regimes: (1) the inner nozzle flow, and (2) the external nozzle flow. In the inner nozzle flow, several factors (such as injector type, geometry, and size) influence the conditions at the injector exit (such as the velocity, the initial sheet or jet thickness, and the angle of droplet dispersion). Right now, we rely on widely-used correlations in determining the initial spray conditions at the injector exit. For a better description, a more accurate analysis is needed which takes into account the physics 
associated with inside bubble growth, cavity formation, and internal turbulence. In the external nozzle flow, the liquid becomes unstable under the influence of aerodynamic instabilities and finally breakup into droplets. When the maximum amplitude of the most unstable wave reaches a critical value, some liquid is stripped of the main liquid core in the form of primary droplets. These droplets may further breakup into smaller droplets due to a process known as the secondary droplet breakup mechanism.

Among the primary atomization models, the following are widely used: (1) the sheet breakup primary atomization model which was developed by [1718] has application in the modeling of sprays generated by pressure swirl atomizers, (2) the blob jet primary atomization model which was developed by Ritz et al [19-21] has application with plane orifice nozzles, and (3) the BLS (Boundary-Layer Stripping) primary atomization model which was developed by Khosla et al [22] has application for a liquid jet in a cross flow. Among the secondary droplet breakup models, the following are widely used: (1) the TAB (Taylor Analogy Breakup) secondary droplet breakup model which was developed by O'Rouke et al [23] has application for lenticular-shaped droplet deformations, and (2) the ETAB (Enhanced TAB) secondary droplet breakup model which was developed by Tanner [24] has application for high-pressure diesel-engine flows.

Most of the coding required for both the primary atomization and secondary droplet breakup models was provided by CFDRC. These models are applicable under both non-superheat and superheat conditions. In the superheated regime, the thermophysical liquid properties are replaced by the twophase properties of a superheated fluid [15].

\section{Flash Atomization Modeling}

There are three components to the atomization modeling of a superheat spray: (1) primary atomization, (2) secondary droplet breakup, and (3) flash induced atomization. Further details on the primary atomization and secondary droplet breakup models can be found in [1]. For the superheated sprays, we have to deal with a third component known as flash induced atomization. We have followed the modeling approach of Lee et al [15] for the flash induced atomization. In what follows we describe some details of their modeling approach.

Flash atomization is a result of rapid evaporation associated with strong nucleation and bubble growth occurring inside of a non-equilibrium twophase fluid [15]. When the void fraction within the rapidly evaporating fluid reaches a certain critical void fraction, the inner liquid core would shatter into pieces. It seemed to have a value of 0.61 based on the research identified in [15]. Incidentally, this condition for criticality also coincides with the packing limit of spheres beyond which it can not accommodate any more bubbles and results in shattering [27]. In order to calculate this state of critical limit, they employed the homogeneous relaxation model (HRM) for calculating the mass fraction of gas, $x$, also known as quality.

$$
\frac{d x}{d t}=\frac{x_{e q}-x}{\theta} ; \theta=\theta_{o} \epsilon^{\alpha} \phi^{\beta} ;
$$

where the values for $\alpha(=-0.54), \beta(=-1.76)$, and $\theta_{o}\left(=6.51 .10^{04} s\right)$ are taken from [28], and the void fraction, $\epsilon$, and the degree of superheat, $\phi$, are defined as follows:

$$
\epsilon=\frac{\rho_{l}-\rho}{\rho_{l}-\rho_{v}} ; \phi=\frac{P_{b}(h)-P}{P_{c}-P_{b}(h)}
$$

Once the critical limit for the void fraction is reached, the resulting droplets produced as a result of flash atomization are obtained by a droplet number density correlation developed by Kawano et al [29].

$$
n=A e^{\frac{-E}{\left(T_{l}-T_{b u b}\right)}} e^{a t+b}
$$

From Eq. (3), the mean droplet size, $\bar{R}$, is calculated by equating total liquid mass before and after the droplets are formed.

$$
\bar{R}^{3}=\frac{1-\epsilon_{c}}{(4 / 3) \pi n}
$$

The solution for Eqs. (1) to (4) as well as the JP8 fluid properties needed in this calculation were obtained by the computer coding provided by UTRC. Also, it is noteworthy that the properties for JP8 were predicted by means of a surrogate model of Violi. Further details can be found in [15].

The flash induced atomization is combined with the primary and secondary droplet breakup models following the approach of Lee et al [15]. The aerodynamic instability mode will atomize the liquid core when the surface disturbance reaches a certain critical value and the flash induced atomization is responsible for shattering the liquid core when the void fraction reaches the critical value. Therefore, the control mechanism depends on whichever mechanism is first responsible for reaching the critical condition. 
Some Additional Aspects of Superheat on Primary $\underline{\text { Atomization }}$

Flash evaporation is known to produce a fine spray with enhanced atomization, increase effective spray cone angle, and decrease spray penetration [11]. Here, we consider the effects of flash evaporation on the sheet breakup primary atomization model by following the approach of Zuo et al [12]. Its effect on the initial droplet size generated immediately after the first ligament breakup, $d_{i s}$, is given as a function of both engine pressure and a superheat parameter as follows:

$d_{i s}=d_{i n}\left(\frac{P}{P_{a t m}}\right)^{0.27}\left[1-\chi\left(\frac{P_{a t m}}{P}\right)^{0.135}\right] \quad 0 \leq \chi\left(\frac{P_{a t m}}{P}\right)^{0.135} \leq 1$

where $d_{i n}$ is the corresponding droplet droplet size under normal evaporating conditions without flash evaporation, and $\chi$ is defined as a superheat parameter as follows:

$$
\chi=\frac{I\left(T_{k}\right)-I\left(T_{b}\right)}{l\left(T_{b}\right)}
$$

where $I$ is the internal energy of the liquid. Its value varies between $0<\chi<1$ with $\chi=0$ referring to zero flash evaporation and $\chi=1$ to full flash evaporation.

In Eq. (5), the increase in $d_{i s}$ due to an increase in engine pressure by a factor of $\left(\frac{P}{P_{a t m}}\right)^{0.27}$ is based on an experimental correlation obtained from Lefebvre [30]. It reflects the influence of chamber pressure on wave propagation as it damps wave growth. But the decrease by a factor of $\left(1-\chi\left(\frac{P_{a t m}}{P}\right)^{0.135}\right)$ is due to a significant reduction in droplet size caused by both cavitation and bubble growth under flash evaporation conditions. It was introduced based on the experimental data obtained from VanDerWege et al [31] and Reitz [32].

As the liquid approaches boiling, it also causes a substantial decrease in both intact liquid core length and core droplet size leading to a modification of the nominal cone angle, $\theta$, as given by

$$
\theta=\theta_{n}+\left(144-\theta_{n}\right) \chi^{2}
$$

where $\theta_{n}$ is in degrees for a spray vaporizing under normal conditions without flash evaporation. This correlation was developed by based on the experimental data of Reitz [32]. Both these correlations were developed in conjunction with the sheet breakup primary atomization model but their validity with other primary atomization models needs further investigation.

\section{VAPORIZATION MODELING OF A SUPERHEATED DROPLET}

In what follows we first provide some details of the two superheat vaporization models that were implemented into NCC.

Superheat Vaporization Model of Zuo, Gomes, \& Rutland [12], and Schmehl \& Steelant [13-14]

It is based on an extension of the classical $D^{2}$ theory. In the classical evaporation model, the thermal energy needed for evaporation is mostly furnished by the external heat transfer from the surrounding gas. Under superheat conditions, the characteristic vaporization time resulting from the external heat transfer from the surrounding gas is of the same order of magnitude as that resulting from the flash evaporation. The energy needed for vaporization at the droplet surface is partly provided by the superheat energy stored within the droplet and it is controlled by the droplet internal heat transfer. The modeling approach differs from the classical droplet vaporization models in three important ways: (1) under superheat conditions, the droplet surface mass fraction, $Y_{f s}$, approaches unity as the droplet surface temperature is maintained at the corresponding liquid boiling temperature; (2) under superheat conditions, all the external heat transfer from the surrounding gas is made available to the vaporization process with no apparent increase in the droplet surface temperature; and (3) the flow of fuel vapor imparted by flash vaporization partly counterbalances the flow generated by external heat transfer and may significantly reduce the energy transferred from the surrounding gas.

Based on the governing equations of conservation for an isolated spherically symmetric droplet, Zuo et al [12] and Schmehl and Steelant [13-14] showed that the total evaporation rate, $\dot{m}_{k}$, can be calculated as

$$
\dot{m}_{k}=\dot{m}_{k, f l a s h}+\dot{m}_{k, t}
$$

where the flash boiled vaporization rate, $\dot{m}_{k, \text { flash }}$, is given by

$$
\dot{m}_{k, \text { flash }}=4 \pi r_{k}^{2} \alpha_{s} \frac{\left(T_{k}-T_{b}\right)}{l_{k}}
$$


where $T_{k}$ is the internal droplet temperature and the overall heat transfer coefficient, $\alpha_{s}\left(=k J / s m^{2}{ }^{o} K\right)$ is given by the Adachi correlation [26]:

$$
\begin{array}{rll} 
& =0.76\left(T_{k}-T_{b}\right)^{0.26} & \left(0 \leq T_{k s}-T_{b} \leq 5\right) \\
\alpha_{s} & =0.027\left(T_{k}-T_{b}\right)^{2.33} & \left(5 \leq T_{k s}-T_{b} \leq 25\right) \\
& =13.8\left(T_{k}-T_{b}\right)^{0.39} & \left(T_{k s}-T_{b} \geq 25\right)
\end{array}
$$

The Adachi correlation is valid over a wide range of superheat conditions.

The vaporization rate due to external heat transfer, $\dot{m}_{k, t}$, in Eq. (8) is given by

$$
\dot{m}_{k, t}=2 \pi r_{k} \frac{k}{C_{p}} \frac{N u}{1+\frac{\dot{m}_{k, \text { flash }}}{\dot{m}_{k, t}}} \ln \left[1+\left(1+\frac{\dot{m}_{k, \text { flash }}}{\dot{m}_{k, t}}\right) B_{t}\right]
$$

where the Spalding heat transfer number, $B_{t}$, and the Nusselt number, $N u$, are given by

$$
\begin{gathered}
B_{t}=\frac{C_{p}\left(T_{g}-T_{k s}\right)}{l_{k, e f f}} \\
N u=2\left(1+0.3 R e^{1 / 2} \operatorname{Pr}_{g}^{1 / 3}\right)
\end{gathered}
$$

where the effective latent heat of vaporization, $l_{k, e f f}$, is given by

$$
l_{k, \text { eff }}=l_{k}+4 \pi \frac{\lambda_{l} r_{k}^{2}}{\dot{m}_{k}}\left(\frac{\partial T_{k}}{\partial r}\right)_{s}
$$

which is an useful parameter as it represents the total energy loss associated with the latent heat of vaporization in addition to the the heat loss to the droplet interior. Finally, the corresponding droplet regression rate, $\frac{d s_{k}}{d t}$, is given by

$$
\frac{d s_{k}}{d t}=-\frac{\dot{m}_{k}}{2 \pi r_{k} \rho_{l}}
$$

This model is valid over an entire range of superheat conditions as long as there is some amount of superheat energy available within the droplet $\left(T_{k}>\right.$ $\left.T_{b}\right)$.

\section{$\underline{\text { Superheat Vaporization model of Lee et al [15] }}$}

This modeling approach is also based on an extension of the classical $D^{2}$-theory but it differs from the previous model of [12-14] in several important ways: (1) neglects the effects of internal nucleation and convection, (2) instead of invoking the Adachi correlation for the flash induced vaporization rate, the heat loss from the droplet interior is modeled by
$\hat{q}_{l}=\frac{T_{\text {interior }}-T_{s}\left(P_{\infty}\right)}{r_{k, t=0}}$, (3) the formulation is valid only when $T_{\infty} \geq T_{b u b}\left(P_{\infty}\right)$, which means for positive Spalding heat transfer numbers.

With the assumptions employed, Lee et al [15] arrive at the following equation for the evaporation rate, $\hat{m}_{v}$.

$$
\hat{m}_{v} \frac{\hat{T}_{\infty}-\hat{T}_{s}}{e^{\hat{m}_{v}}-1}=\hat{m}_{v} \hat{L}-\hat{q}_{l}
$$

where

$\hat{T}=C_{p g} T / L_{r}, \hat{m}_{v}=\left(4 \pi r_{k}^{2} \rho_{g} u\right) /\left(4 \pi \lambda_{g} r_{k, t=0} / C_{p g}\right)$, $\hat{L}=L_{k} / L_{r}$. The solution for the above equation is obtained by employing the standard Newton's iteration.

It is noteworthy that because of the assumptions invoked in this model, the applicability of this model may be limited in several important ways: (1) our experience shows that the assumption of $T_{\infty} \geq T_{b u b}\left(P_{\infty}\right)$ becomes too restrictive in most non-reactive calculations and also in some regions of most reactive spray calculations, and (2) the $\hat{q}_{l}$ term is modeled based on the assumption that the overall droplet life is very short (sub millisecond range) but in most moderate superheat conditions the droplet lifetimes are on par with those vaporizing under nonsuperheat conditions. So its use is likely to be restricted for the modeling of smaller droplets produced after flash induced atomization.

The solution for Eq. (16) and all the JP8 fluid properties needed in this calculation were also obtained by the computer coding provided by UTRC.

\section{Vaporization Model Valid Under Non-Superheat}

$$
\underline{\text { Conditions }}
$$

Under moderate initial superheat conditions, only a fraction of the vaporization takes place under superheat conditions $\left(T_{k}>T_{b}\right)$ and the remainder takes place under non-superheat evaporating conditions $\left(T_{k} \leq T_{b}\right)$. So there is a need to revert back to a vaporization model valid under stable evaporating conditions when the internal droplet temperature approaches the boiling temperature. In the present calculations, the vaporization rate under normal evaporating conditions is evaluated by means of a simplified classical $D^{2}$-theory:

$$
\dot{m}_{k}=2 \pi r_{k} \rho_{g} D_{f g s} S h \ln \left(1+B_{k}\right)
$$

where the Spalding mass transfer number, $B_{k}$, is given by 


$$
B_{k}=\frac{\left(y_{f s}-y_{f}\right)}{\left(1-y_{f s}\right)}
$$

where $y_{f s}$ is the mass fraction of the fuel species at the the droplet interface, $y_{f}$ is the mass fraction of the fuel species in the surrounding gas, and the Sherwood number, $S h$, is given by

$$
S h=2\left(1+0.3 R e^{1 / 2} S c_{g}^{1 / 3}\right)
$$

\section{Internal Droplet Temperature Calculation}

Our experience with the validation studies showed us that there is a definite need to include a calculation involving the internal droplet temperature valid under both superheat and normal evaporating conditions. In our present calculations, it was evaluated by means of a simple infinite conductivity model.

$$
\begin{gathered}
\frac{d T_{k}}{d t}=\frac{3\left[l_{k, \text { eff }}-l_{k}\right]}{2 C_{p l} r_{k}^{2}} \frac{d s_{k}}{d t} \\
\text { if } T_{k}<T_{b}, \quad \text { and } \\
\frac{d T_{k}}{d t}=-\frac{3 \alpha_{s}}{r_{k} \rho_{l} C_{p l}}\left(T_{k}-T_{b}\right)
\end{gathered}
$$

( for the superheat model of $[12-14]$ )

$$
\begin{aligned}
& \text { or } \\
& \frac{d T_{k}}{d t}=-\left.\frac{3 \lambda_{l}}{r_{k} \rho_{l} C_{p l}} \frac{\partial T}{\partial r}\right|_{l s}
\end{aligned}
$$

(for the superheat model of [15])

$$
\text { if } T_{k} \geq T_{b}
$$

\section{RESULTS \& DISCUSSION}

A Flashing Jet Generated by a Cylindrical Nozzle

This investigation is under taken mainly to test the following models: (1) the superheat vaporization model of [12-14], (2) the blob-jet primary atomization model [19-21], \& (3) the ETAB secondary droplet breakup model [24-25]. The experimental data for this validation was provided by Yildiz et al [33-34]. It contained data for two-phase jet flows generated by the sudden release of pressurized R134A from cylindrical nozzles of different sizes. In our present calculations, we have focused mainly on a case involving the $1 \mathrm{~mm}$ nozzle for which the most extensive data were reported.

It is based on a $2 \mathrm{~d}$-axisymmetric geometry: $2 \mathrm{~d}-$ axisymmetric. All the calculations were performed on a grid with 79101 triangular elements (non-reacting, turbulent air flow).

At the start of jet dispersion, the pressurized liquid would undergo some expansion due to the entrainment of surrounding air and vaporization of the pressurized liquid depending on the degree of superheat. Because of this expansion, the effective size of the expanded jet would be larger than the orifice exit. Based on the experimental observation, the initial size of the jet at the point of jet breakup was estimated to be about $9 \mathrm{~mm}$. The initial gas velocity was prescribed based on the experimental correlation reported by Yildiz et al [34]. The initial gas temperature $298 \mathrm{~K}$, turbulence kinetic energy, $\mathrm{k}=1 \&=$ $10 \mathrm{~m}^{2} / \mathrm{s}^{2}$. The liquid is R134A, a refrigerant. The injector has a diameter of $0.001 \mathrm{~m}$ and is located in the middle of a center-body configuration. The initial droplet velocity was estimated to be $34 \mathrm{~m} / \mathrm{s}$ based on the pressure drop across the injector. The initial liquid temperature is $293 \mathrm{deg}$. $\mathrm{K}$ which corresponds to a superheat temperature of $46 \mathrm{deg}$. C.

The results for this case were reported in our earlier paper [16]. The predicted profiles for both gas and droplet velocities show a reasonable agreement with the measured data, and exhibit a self-similar behavior as reported in the literature. The predicted droplet sizes mainly fall short of experimental data in the central region of the spray. Away from the central region, the predicted sizes are in reasonable agreement with the experimental behavior. Both the predictions and experimental data showed that a considerable amount of vaporization takes place under non-superheat conditions.

\section{Parker-Hannifin Pressure Swirl Atomization}

This investigation is undertaken mainly to test the following models: (1) Sheet-breakup primary atomization model [17-18], \& (2) ETAB secondary droplet breakup model [24-25]. The experimental data for this validation was provided by Ref. [35]. It is based on a 2d-axisymmetric geometry. For this case both the grid and the initial conditions were provided by CFDRC (non-reacting, turbulent air flow). The experimental conditions for the gas phase are 
specified as follows: (1) the axial velocity is assumed to be uniform at $1.2 \mathrm{~m} / \mathrm{s},(2)$ the radial velocity profile is prescribed by means of an interpolation from the following three points: $\mathrm{y}=0.019 \mathrm{~m}, \mathrm{v}=-0.9 \mathrm{~m} / \mathrm{s}$, $\mathrm{y}=0.1 \mathrm{~m}, \mathrm{v}=-0.5 \mathrm{~m} / \mathrm{s}, \& \mathrm{y}=0.3 \mathrm{~m}, \mathrm{v}=0,(3)$ the gas temperature $=300 \mathrm{~K}, \&$ (4) the turbulence kinetic energy, $\mathrm{k}=1 \&=10\left(\mathrm{~m}^{2} / \mathrm{s}^{2}\right)$. The liquid phase conditions are specified as follows: (1) the liquid fuel is $\mathrm{C} 12 \mathrm{H} 23$, (2) the injector has a diameter of $0.0012 \mathrm{~m}$ and is located in the middle of a center-body configuration, (3) the liquid mass flow rate is $0.00125 \mathrm{~kg} / \mathrm{s}$, (4) the internal pressure drop across the atomizer is $344500 \mathrm{~Pa}, \&$ (5) the initial liquid temperature is 300 $\mathrm{K}$.

The experimental conditions were based on the non-superheat evaporating conditions. The reported experimental results involved droplet axial velocities, droplet radial velocities, and droplet sizes. The comparisons for this case were also reported in our earlier paper [16]. The predicted results were in reasonable agreement but mostly underestimate the the experimental data.

We have also completed two more calculations for the same case of Parker Hannifin but performed under non-reacting superheat conditions. In one, the SVM (Superheat Vaporization Model) of [12-14] was employed and in the second the SVM of [15] was employed. In both calculations, the properties of $\mathrm{C} 12 \mathrm{H} 23$ were replaced by the JP8 properties of a superheated fluid. They were calculated based on the coding provided by UTRC [15]. The specified initial liquid temperature was raised to $520 \mathrm{deg}$. K. For the JP8, the boiling temperature at the normal pressure is about 468 deg. K.

The global structure of the non-reacting spray obtained from both the two calculations are shown in Fig. 1. The differences between the two calculations are considerable: (1) The results from the SVM of [12-14] showed a temperature variation ranging from 270 to about $430 \mathrm{deg}$. K. Initially there is an increase in the gas temperature near the spray region from the superheated droplet. While some of the smaller droplets vaporize completely under superheat conditions, some of the larger droplets cool off below the boiling temperature after depleting all of the superheat energy from the droplet interior. Further vaporization from those larger droplets tend to lower the temperatures in the surrounding gas below the corresponding droplet surface temperature. This effect can be seen downstream in a small central region where temperatures fall below the initial specified gas temperature of $300 \mathrm{deg}$. K. This behavior of evaporative cooling is similar to what we have seen in the validation case of Yildiz et al [16]. (2) The results from the SVM of [15] show the gas temperatures to range between 300 to $355 \mathrm{deg}$. K. This calculation also shows a slight increase in the gas temperature in the central region near nozzle exit. In this calculation the gas temperatures mostly stay above the initial specified gas temperature of $300 \mathrm{deg}$. K. It is because this superheat model is only valid for positive Spalding numbers; therefore, makes its applicability more difficult for the modeling of a non-reacting spray.

We have also completed two more calculations for the same case but performed under reacting superheat conditions. Again in one calculation the SVM of [12-14] was employed and in the second the SVM of [15] was employed. All other conditions are maintained the same as in the non-reacting superheat calculations.

The global features of the reacting spray obtained from the reacting calculations are shown in Fig. 2. The spray particle distribution appears to be similar in both calculations. The gas temperature ranges between 300 to $2100 \mathrm{deg}$. K. In both calculations most of the combustion takes place downstream of the spray in a predominantly diffusion-controlled flame. However, in the calculation involving Lee et al [15], the high temperature region extends further upstream into the inner central region of the hollowcone spray.

\section{Swirl Stabilized Reacting Spray Generated by a Single Element LDI Experiment}

This investigation is undertaken to test the following models: (1) the Sheet breakup primary atomization model [17-18], \& (2) the TAB secondary droplet breakup model [23]. The experimental data for this validation was provided by Ref. [36]. Fig. 3 shows the test section of the experiment reported in [36]. The air passes through a six helicoidal vane swirler followed by a converging-diverging venturi before entering the combustor. The air mass flow rate is $0.49 \mathrm{~kg} / \mathrm{min}$., and at the inlet, air speed $=20.4 \mathrm{~m} / \mathrm{s}$, $\mathrm{T}=294.3 \mathrm{~K}, \mathrm{P}=101325 \mathrm{~Pa}$. The fuel nozzle is located at the middle of the centerbody and it is a ParkerHannifin, 90-deg. hollow cone, pressure swirler. The liquid fuel is Jet-A, the liquid mass flow rate 0.025 $\mathrm{kg} / \mathrm{min}$, and the initial liquid temperature $475 \mathrm{~K}$. The internal pressure drop across the atomizer is 350000 
$\mathrm{Pa}$ which leads to an initial liquid velocity of about $22 \mathrm{~m} / \mathrm{s}$.

The results are based a 3D calculation with a grid size of 833024 elements. It makes use of the following models for the gas-phase: the standard k-epsilon turbulence model, a a single-step reduced chemical kinetic mechanism, and the eddy-breakup turbulence/chemistry model. The experimental conditions were based on the non-superheat evaporating conditions. The reported experimental results involved gas and droplet velocities (axial, radial, and tangential), \& droplet sizes. The comparisons for this case were also reported in our earlier paper [16]. For this case, the predicted gas-phase results underestimate both size and location of the central recirculation region but the predictions provide better agreement for both droplet size and velocities.

We have also completed two more calculations for this case involving superheat conditions. In one, the SVM of [12-14] was employed, and in the second, the SVM of [15] was employed. In both calculations, the liquid properties of the jet-a fuel were replaced by the two-phase properties of JP8. Also, the specified initial liquid temperature was raised to $520 \mathrm{deg}$. K.

Figs. 4 to 10 show the results for both gas and droplet velocities, and droplet sizes. Shown here are the comparisons between the experimental data, the predicted obtained from the corresponding nonsuperheat experimental conditions, as well as the predicted results obtained from the two different superheat calculations. The comparisons for gas axial velocities at different axial locations are shown in Fig. 4 , and the comparisons for the radial and tangential velocities are shown in Figs. 5 and 6, respectively. The gas velocities obtained from the superheat conditions are similar to those obtained from the nonsuperheat conditions and they all underestimate both size and location of the central recirculation. The predictions could be improved by taking into account of the unsteady nature of fluid flow and also by incorporating a better chemical kinetic mechanism and chemistry/turbulence model.

The comparisons for the droplet sizes are shown in Fig. 7 at four different axial locations. The comparisons between the experimental data and the predictions from the non-superheat calculation are in good agreement. It is also noteworthy that the radial spreading rate of the spray is well predicted. As you move progressively further downstream, more droplets start disappearing from the the central region. It is because of the rise in the gas tempera- ture to near flame temperature which leads to faster evaporation. But the comparisons differ significantly with the results obtained from the superheat calculations. The results from both the superheat vaporization models are mostly similar. At the first axial location, the predicted droplet sizes from the superheat conditions are higher than the experimental data in the the central region. The reason for this increase could partly be attributed to a decrease in the liquid density caused by a rapid bubble growth in the superheated fluid. This would lead to a decrease in the liquid breakup length/time because of its $\sqrt{\frac{\rho_{l}}{\rho_{g}}}$ dependence which in turn leads to an increase in the initial product droplet size because of its inverse relationship to the liquid breakup time. But at the next (second) axial location, the drop sizes mostly fall below the experimental results. Further downstream, the effect of superheat conditions is more evident as the predicted droplet sizes fall significantly below the experimental data.

Fig. 8 shows the droplet mean axial velocity comparisons at six different axial locations. Shown are the predicted results as well as the experimental data for two different droplet-size groups: 0-15 microns and 60-75 microns. The data for the $0-15 \mathrm{mi}-$ crons represent the velocities of the smallest droplet sizes and the data for the 60-75 microns represent the velocities of the largest droplet sizs. Our predicted results are expected to fall somewhere in between the two droplet-size groups but they are expected to fall closer to the 60-75 microns as the predicted results are based on the mean-size (SMD) droplet representation. The comparisons with the non-superheat calculation are mostly in good agreement and fall mostly closer to the large-size droplet group but for some underestimation observed in the middle of the first axial location, and the outer region of the second axial location. The results from the superheat calculations are also mostly in similar agreement in the first three axial locations but the differences grow in the last axial locations where fewer droplets are present due to faster vaporization under superheat condtiions. Also, the axial velocities are underpredicted in the last two axial locations. Fig. 9 shows the droplet radial velocity comparisons. There seems to be a reasonable agreement between the predicted and experimental results but for some underestimation observed in the middle of the first axial location, and the outer regions of the second and third axial locations. Also, it is interesting to note that the radial velocities for 
the small-size droplets are much higher than the corresponding larger-size droplets in the first two axial locations. It is because the smaller droplets tend to follow the gas velocity where the radial gas velocities are much higher because of swirl-induced recirculation. The mean droplet tangential velocity comparisons are shown in Fig. 10. The predicted results fall mostly closer to the experimental data of the large-size droplets at the first three axial locations. They mostly underpredict the experimental data in the next three locations but the superheat results show a slightly better improvement. It is because smaller droplets resulting from increased vaporiztion due to superheat tend to follow the gas velocity. The comparisons could perhaps be improved by providing an additional swirl component to the initial liquid velocity as no swirl component was specified in the present calculations.

\section{CONCLUDING REMARKS}

The paper describes complete details of a solution procedure that was implemented into NCC for the modeling of a superheated spray. The modeling approach was used in the validation of a flashing cylindrical jet, and in the model-accuracy assessment studies based on a pressure swirl atomizer to examine the differences between the two superheat vaporization models, and a single-element LDI reacting case to evaluate the differences between the non-superheat and superheat conditions.

\section{REFERENCES}

1. M.S. Raju, LSPRAY-III: A Lagrangian Spray Module, NASA/CR-2008-215290, NASA Glenn Research Center, Cleveland, Ohio, July 2008.

2. M.S. Raju, EUPDF-II: An Eulerian Joint Monte Carlo PDF Module, NASA/CR-2004-213073, NASA Glenn Research Center, Cleveland, Ohio, April, 2004.

3. Raju, M.S., "CFD Modeling of Superheated Sprays," AIAA-2009-1187, the 47th Aerospace Sciences Meeting, Orlando, Florida, January 58, 2009.
4. Raju M.S., and Sirignano, W.A., "MultiComponent Spray Computations in a Modified Centerbody Combustor," Journal of Propulsion and Power, Vol. 6, No. 2, March-April 1990.

5. Raju, M.S., "AGNI-3D: A Computer Code for the Three-Dimensional Modeling of a Wankel Engine," Computers in Engine Technology, Proceedings IMechE, London, United Kingdom, pp. 27-37, 1991.

6. Raju, M.S., "Heat Transfer and Performance Characteristics of a Dual-Ignition Wankel Engine," Journal of Engines, the 1992 SAE Transactions, Section 3, pp. 466-509.

7. M.S. Raju, Application of Scalar Monte Carlo Probability Density Function Method For Turbulent Spray Flames, Numerical Heat Transfer, Part A, vol. 30, pp. 753-777, 1996.

8. M.S. Raju, Current Status of the Use of Parallel Computing in Turbulent Reacting Flows: Computations Involving Sprays, Scalar Monte Carlo Probability Density Function \& Unstructured Grids, Advances in Numerical Heat Transfer, vol. 2, ch. 8, pp.259-287, 2000.

9. M.S. Raju, Scalar Monte Carlo PDF Computations of Spray Flames on Unstructured Grids With Parallel Computing, Numerical Heat Transfer, Part B, No. 2, Vol. 35, pp. 185-209, March 1999.

10. M.S. Raju, On the Importance of Chemistry/Turbulence Interactions in Spray Computations, Numerical Heat Transfer, Part B: Fundamentals, No. 5, Vol. 41, pp. 409-432, 2002.

11. Lucas, K.D., Tseng, C.C., Pourpoint, T.L., Lucht, R.P., and Anderson, W.E., "Imaging Flashing Injection of Acetone at Jet Engine Augmentor Conditions," AIAA Paper 2007-1182, 45th AIAA Aerospace Sciences Meeting and Exhibit, Reno, Nevada, Jan. 8-11, 2007.

12. Zuo, B., Gomes, A.M., and Rutland, C.J., "Modeling Superheated Fuel Sprays and Vaporization," Int. J. Engine Research, vol. 1, no. 4, pp. 321-336. 
13. Schmehl, R, and Steelant, J., "Flash-Evaporation of Oxidizer During Start-Up of an Upper-Stage Rocket Engine," AIAA Paper 2003-5075, 39th AIAA/ASME SAE/ASEE Joint Propulsion Conference and Exhibit, Huntsville, Alabama, July 20-23 2003.

14. Schmehl, R, and Steelant, J., "Evaluation of Oxidizer Temperature Drop in a Combustion Chamber," 4th International Conference on Launcher Technology "Space Launcher Liquid Propulsion, Liege, Belgium, December 3-6 2002.

15. Lee J., Fotache C., Gopalakrishnan, S., \& Schmidt, D., "Validated tools for Low Emissions Injector Design Using Superheated/Supercritical Fuels," NASA/CR-Year-2010/NNC07CB05C, Glenn Research Center, Cleveland, Ohio.

16. Raju, M.S., \& Bulzan, D., "Assessment of Some Atomization Models used in Spray Calculations," ICCES1120110131487, Nanjing, China, 18-21 April, 2011, also as NASA/TM-2011217029, Glenn Research Center, Cleveland, Ohio, March 2011.

17. Schmidt, D.P., Nouar, I., Senecal, P.K., Hoffman, J., Rutland, C.J., Martin. J., \& Reitz, R.D., "Pressure-Swirl Atomization in the Near Field," 1999 SAE Congress, SAE 1999-01-0496.

18. Senecal, P.K., Schmidt, D.P., Nouar, I., Rutland, C.J., \& Reitz, R.D., "Modeling High Speed Viscous Liquid Sheet Approximation," 1998.

19. Reitz, R.D., \& Bracco, F.V., "Mechanism of Atomization of a Liquid Jet," Phy. Fluids, Vol. 25, ch. 10, Oct., 1982.

20. Reitz, R.D., and Diwakar, R. "Structure of HighPressure Fuel Sprays," SAE paper 870598, 1987.

21. Reitz, R.D., "Computer Modeling of Sprays," Spray Technology Short Course, Pittsburg, PA May 7, 1997.

22. Khosla, S., and Crocker, D.S., "CFD Modeling of the Atomization of Plain Jets in Cross Flow for Gas Turbine Applications"' IGTI Turbo Expo: Combustion \& Fuels, GT2004-54269, Vienna, Austria, June 2004.

23. O'Rourke, P.J., and Amsden, A.A., "The TAB Method for Numerical Calculation of Spray Droplet Breakup," SAE Technical Paper 872089, 1987.
24. Tanner, F.X., "Liquid Jet Atomization and Droplet Breakup Modeling of Non-evaporating Diesel Fuel sprays," SAE Technical Paper 970050, 1998. Also SAE 1997 Transactions: Journal of Engines, Vol. 106, Sec. 3, pp. 127140, 1998.

25. Tanner, F.X., "A Cascade Atomization and Drop Breakup Model for the Simulation of HighPressure Liquid Jets," SAE Paper 2003-01-1044, 2003.

26. Adachi, M., McDonnel, V.G., Tanaka, D., Senda, J, and Fujimoto, H., "Characteristics of Fuel Vapor Concentration Inside a Flash Boiling Spray," SAE Paper 970871, 1997.

27. Sher, E., \& Elata, C., "Spray Formation from Pressure Cans by Flashing," Ind. Eng. Chem. Process Des. Dev., Vo. 16, number 2, pp. 237242, 1977.

28. Downar-Zapolski, P., Bilicki, Z., Bolle, L., \& Franco, J., "The Non-Equilibrum Model OneDimensional Flashing Liquid Flow," Int. J. of Multiphase Flow, Vol. 22, No. 3, pp. 473-483, 1996.

29. Kawano, D., Ishii, H., Suzuki, H., Gotto, Y., Odaka, M., \& Senda, J., "Numerical Study on Flash-Boiling Spray of Multicomponent Fuel," Heat-Transfer-Asian Research (Wiley Periodicals, Inc.), Vol. 35, No. 5, pp. 369-385, 2006.

30. Lefebvre, A., "Atomization and Sprays," Hemisphere Publishing Company, New York, pp. 165222,1989 .

31. VanDerWege, B.A., Lounberry, T.H., and Hochgreb, S., "Numerical Modeling of Fuel Sprays in DISI engines Under Early-Injection Operating Conditions," SAE Paper 2000-010273, 2000.

32. Reitz, R.D., "A Photographic Study of FlashBoiling Atomization," Aerosol Science Technology, Vol, 12, pp. 561-569, 1990.

33. Yildiz, D., Rambaud, P., Van Beeck, J., Buchlin, J.-M., "Characterization of Superheated Liquid Jet Atomization Phase Doppler Anemometer (PDA) and High-Speed Imaging," Proceedings of FEDSM2006: 2006 ASME Joint U.S.European Fluids Engineering Summer Meeting, July 17-20, 2006, Miami, Florida. 
34. Yildiz, D., Rambaud, P., Van Beeck, J., Buchlin, J.-M., "Evolution of the Spray Characteristics in Superheated Liquid Jet Atomization in Function of Initial Flow Conditions," ICLASS-2006, Paper ID ICLASS06-122, Aug. 27-Sept 1, 2006, Kyoto, Japan.

35. Benjamin, M.A., Crocker, D.S., "Spray Characterization of a Relatively High Flow Simplex Atomizer Using Experiment and CFD," 32th Joint Propulsion Conference, AIAA paper 963165, July 1996.

36. Cai, J., Jeng, S.M., Tacina, R., "The Structure of a Swirl Stabilized Reacting Spray Issued From an Axial Swirler," 43rd AIAA Aerospace Sciences Meeting \& exhibit, AIAA 20424, January 2005. 


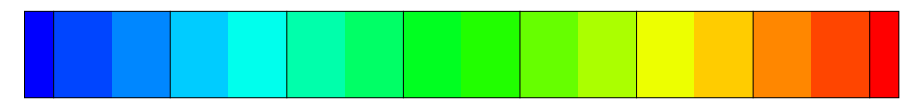

T: 270296321347373399424450

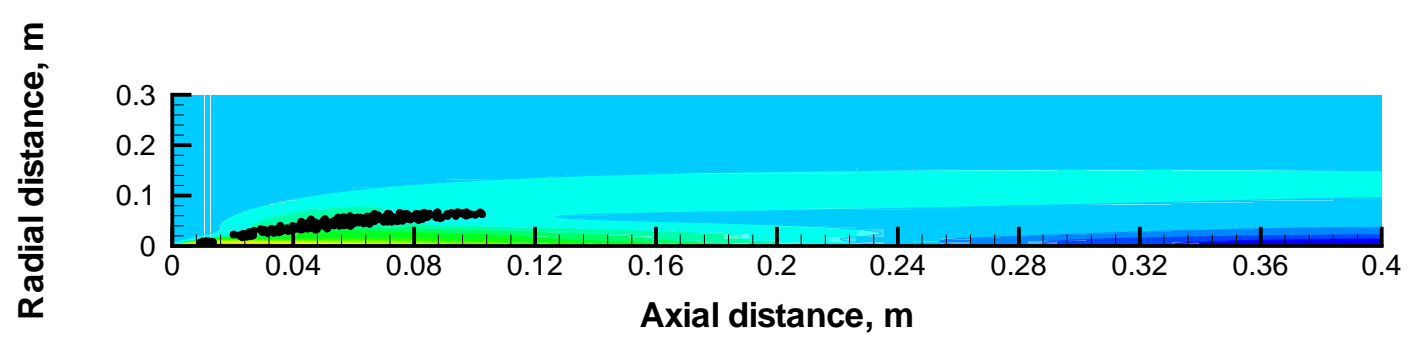

(a) SVM of Zuo et al [12-14].

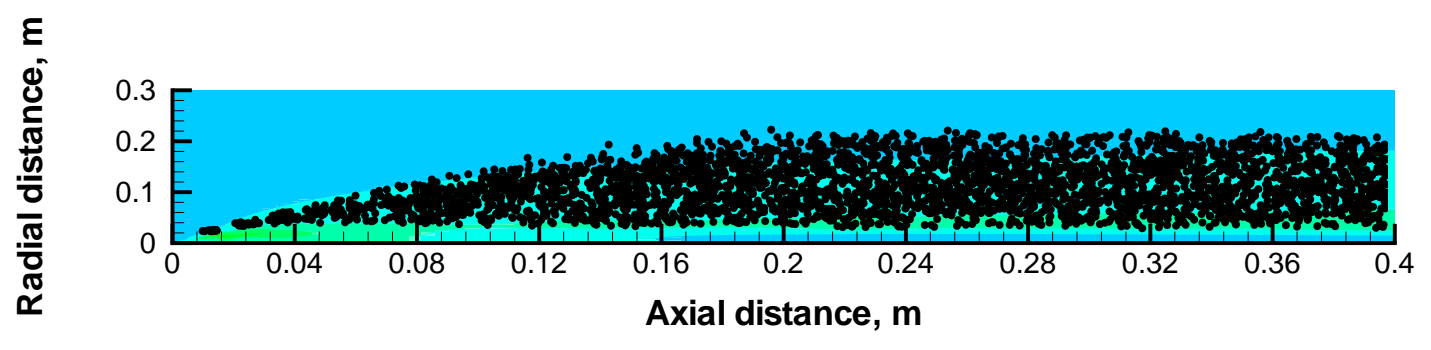

(b) SVM of Lee et al [15].

Fig. 1 Global structure of a non-reacting spray generated by a Parker-Hannifin pressure-swirl atomizer under superheat conditions. 

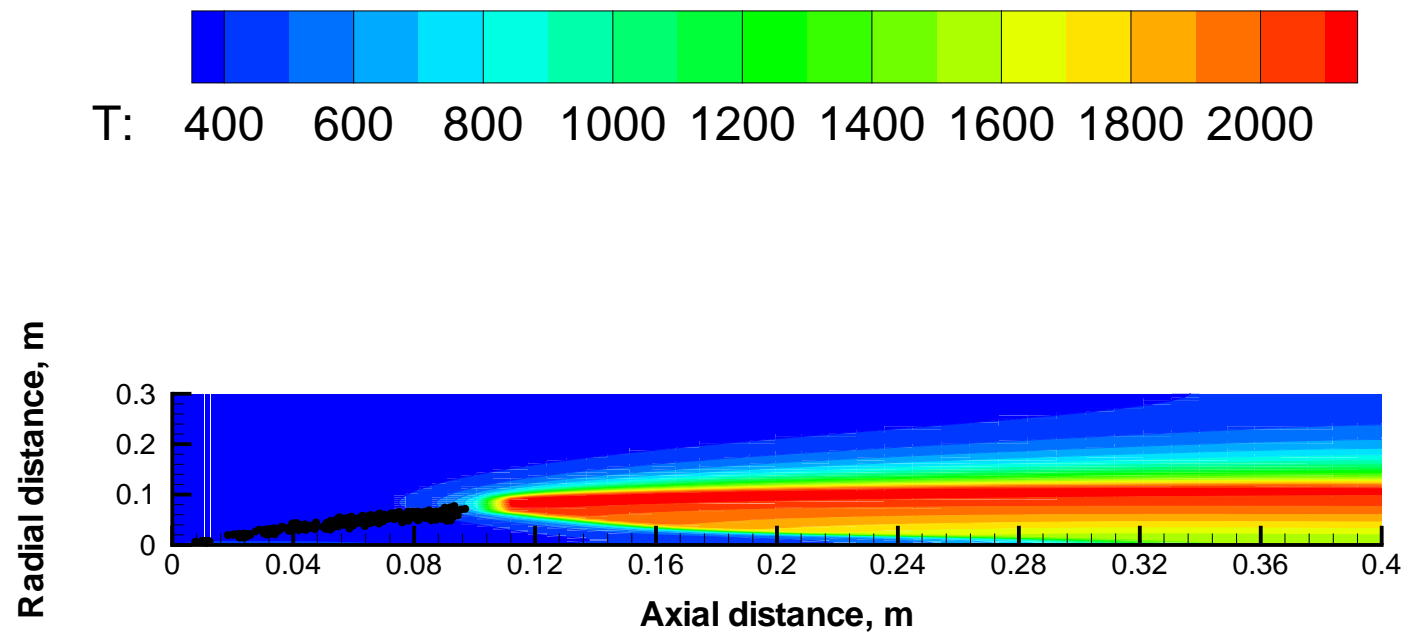

(a) SVM of Zuo et al [12-14].

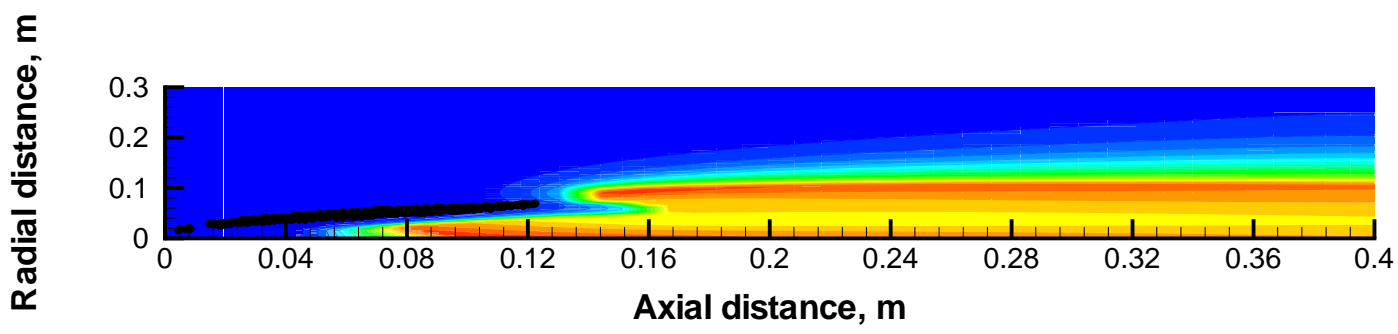

(b) SVM of Lee et al [15].

Fig. 2 Global structure of a spray flame generated by a Parker-Hannifin pressure-swirl atomizer under superheat conditions. 


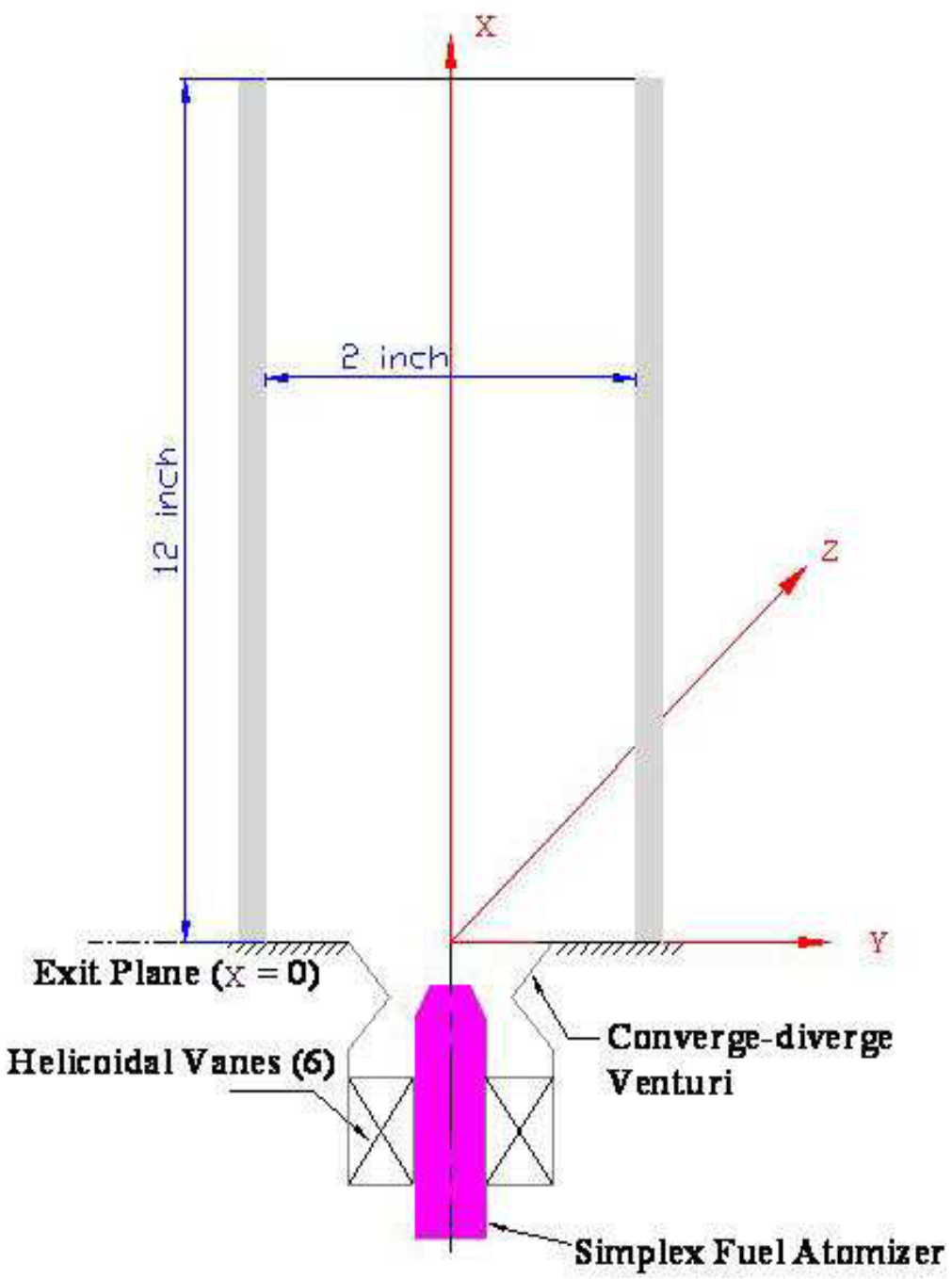

Fig. 3 Test setup of the single-element LDI experiment (taken from Cai et al [36]). 

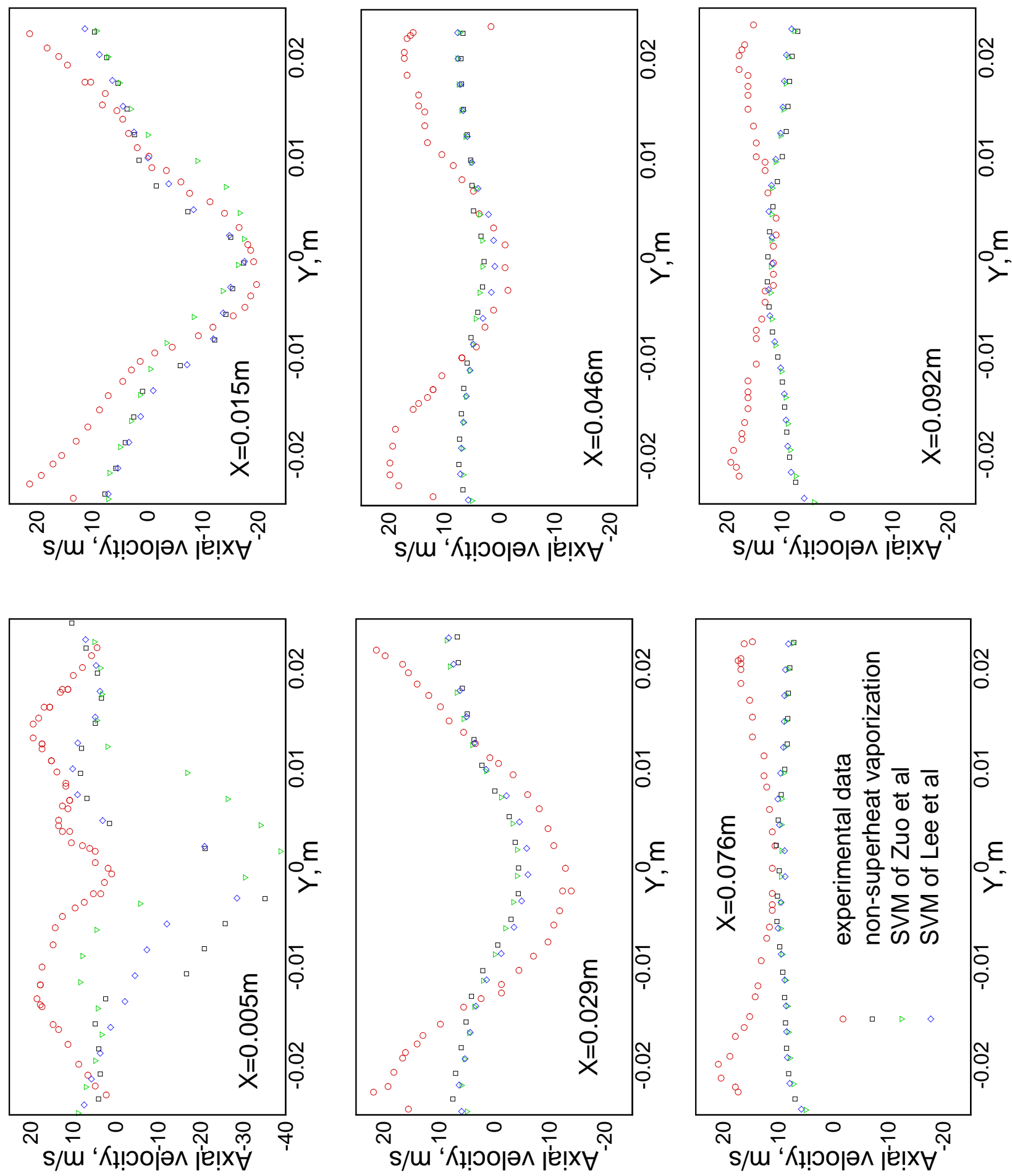

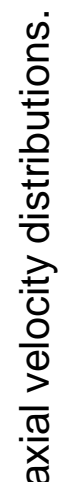

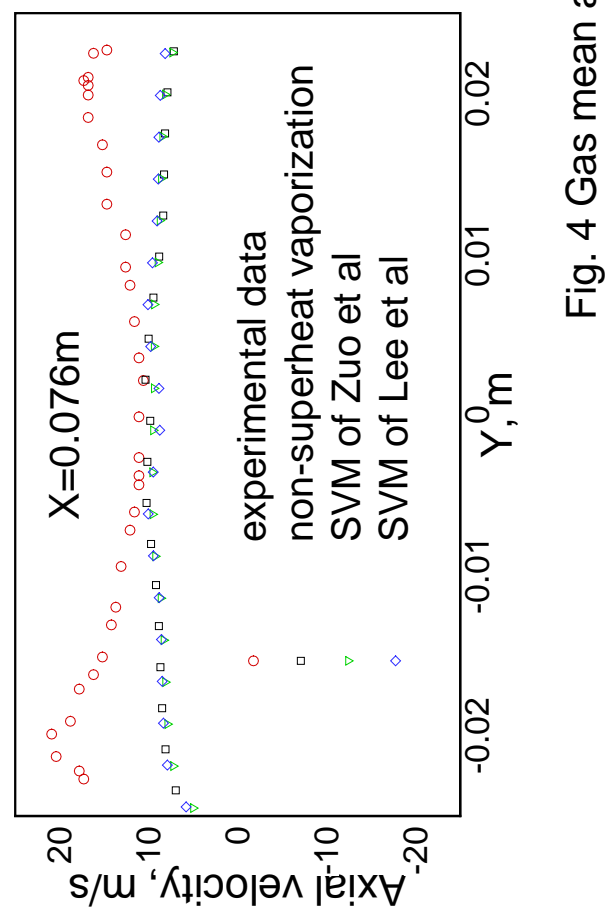



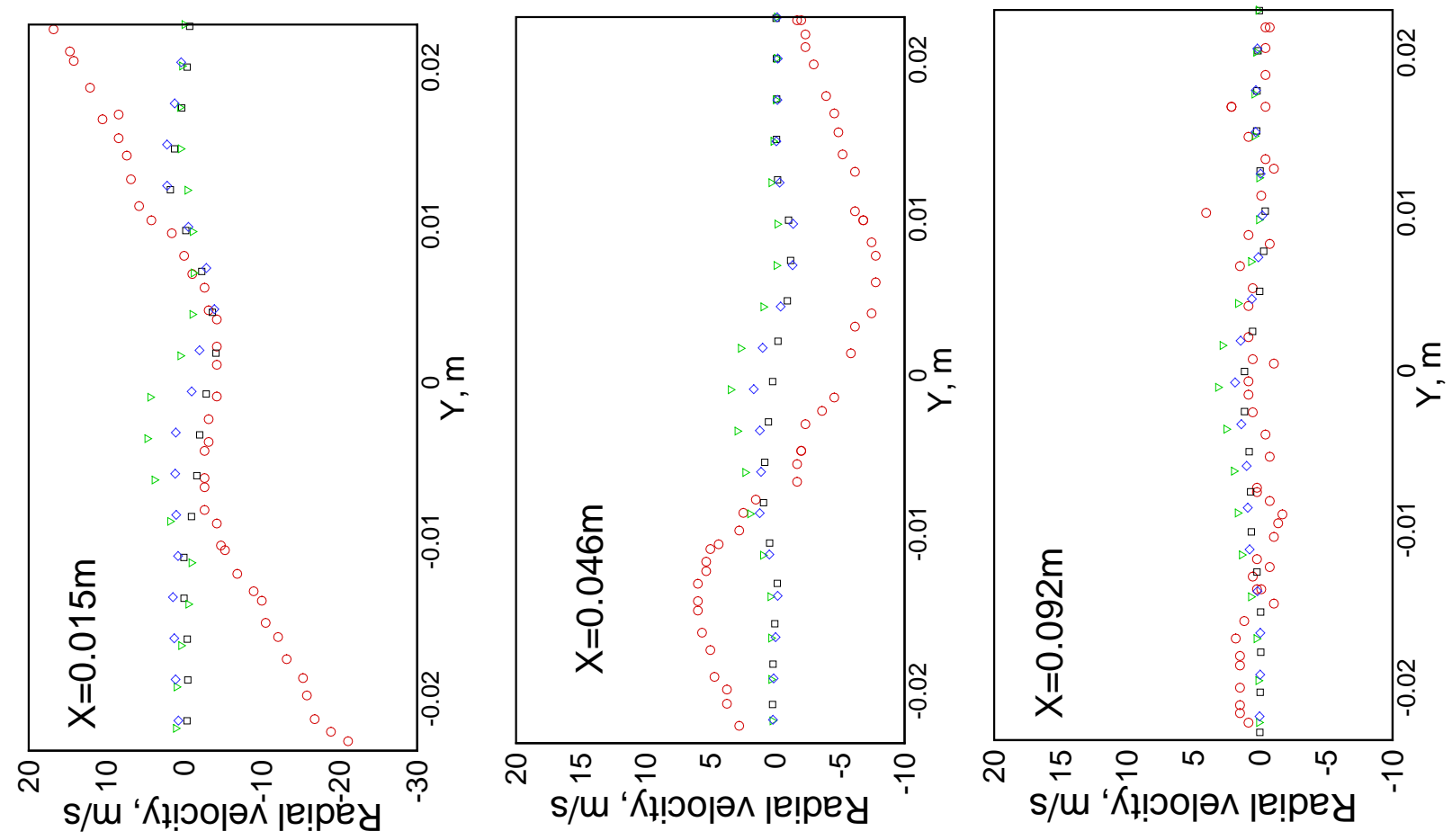

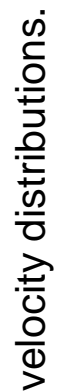
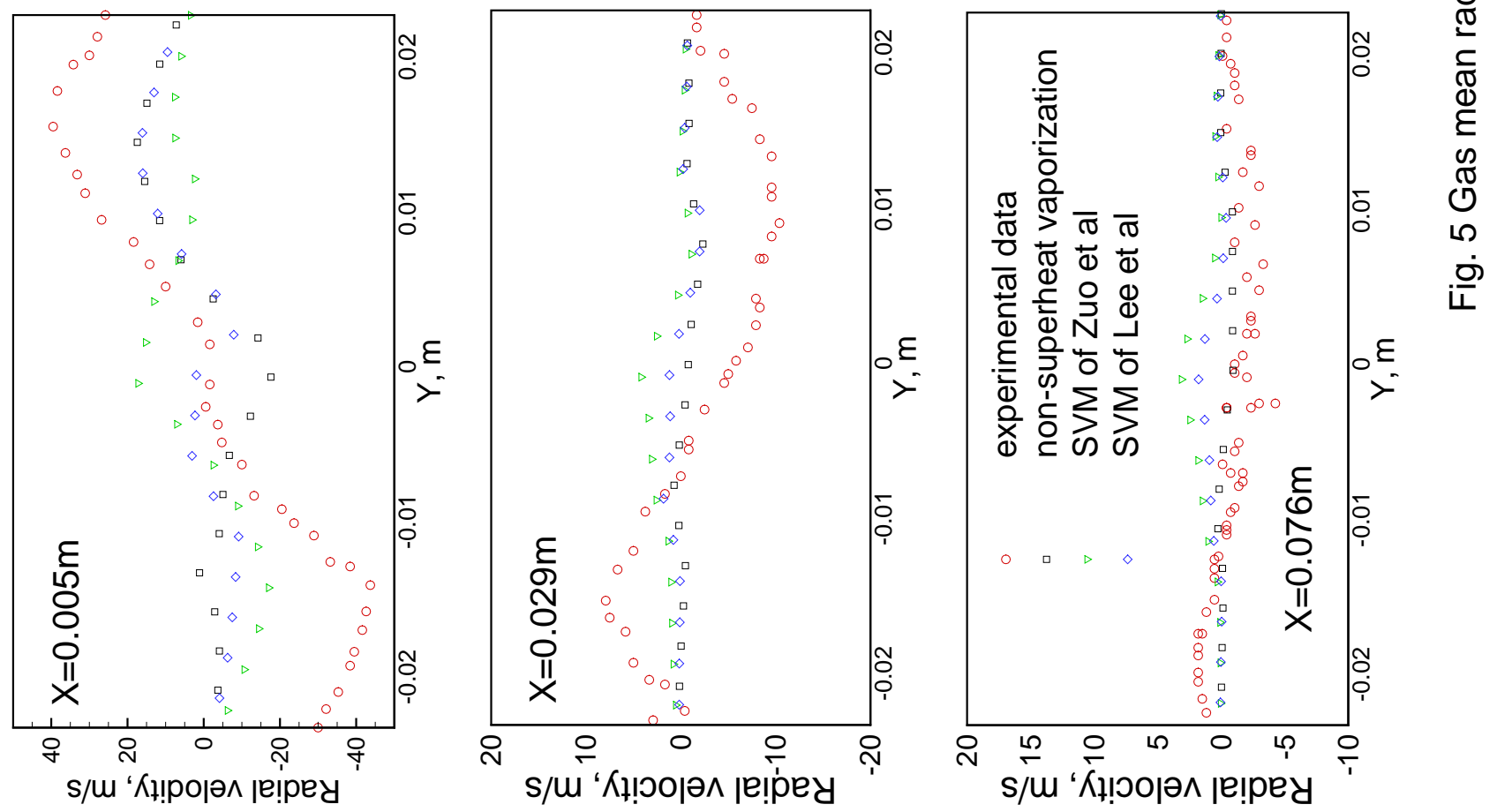

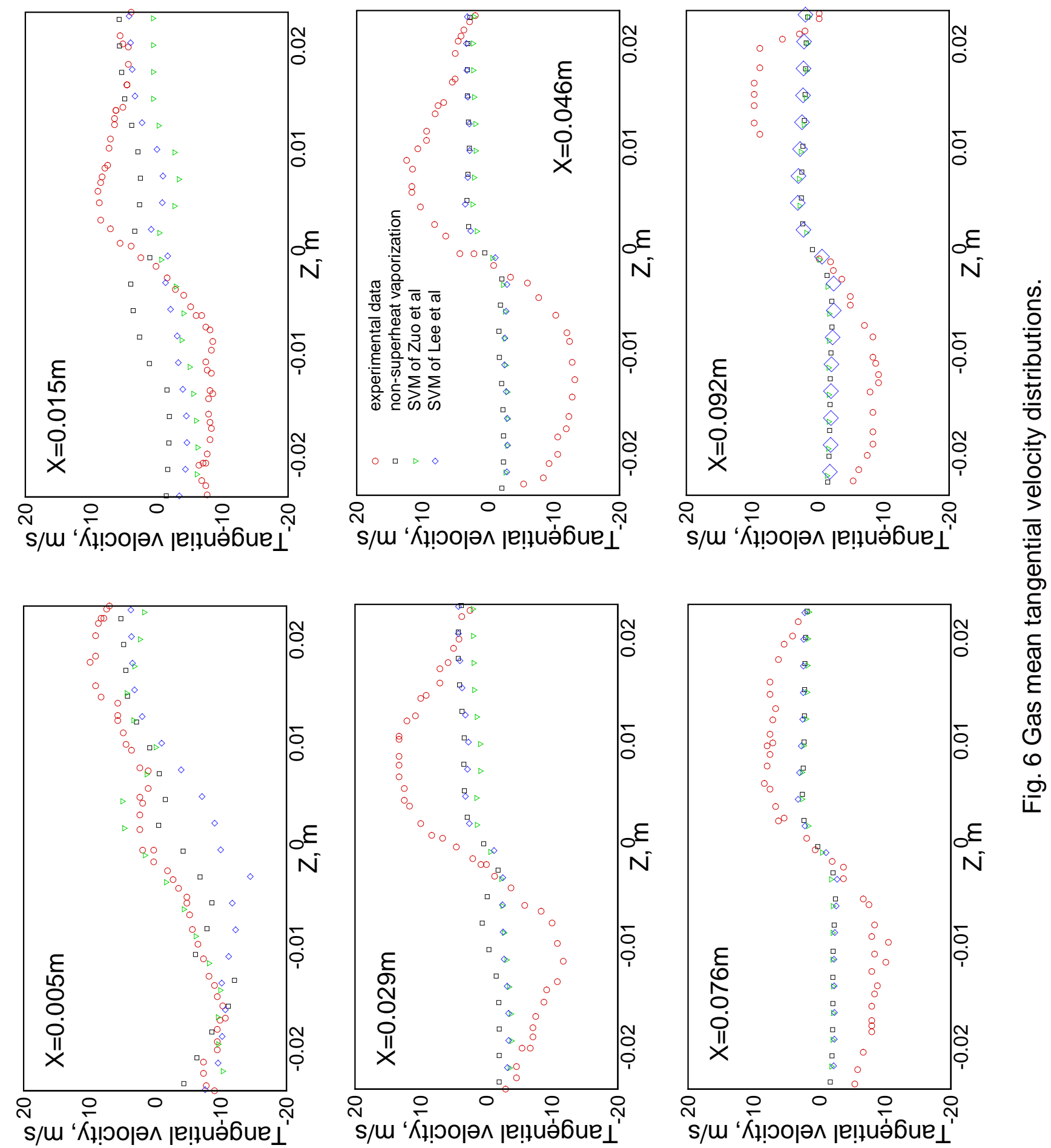

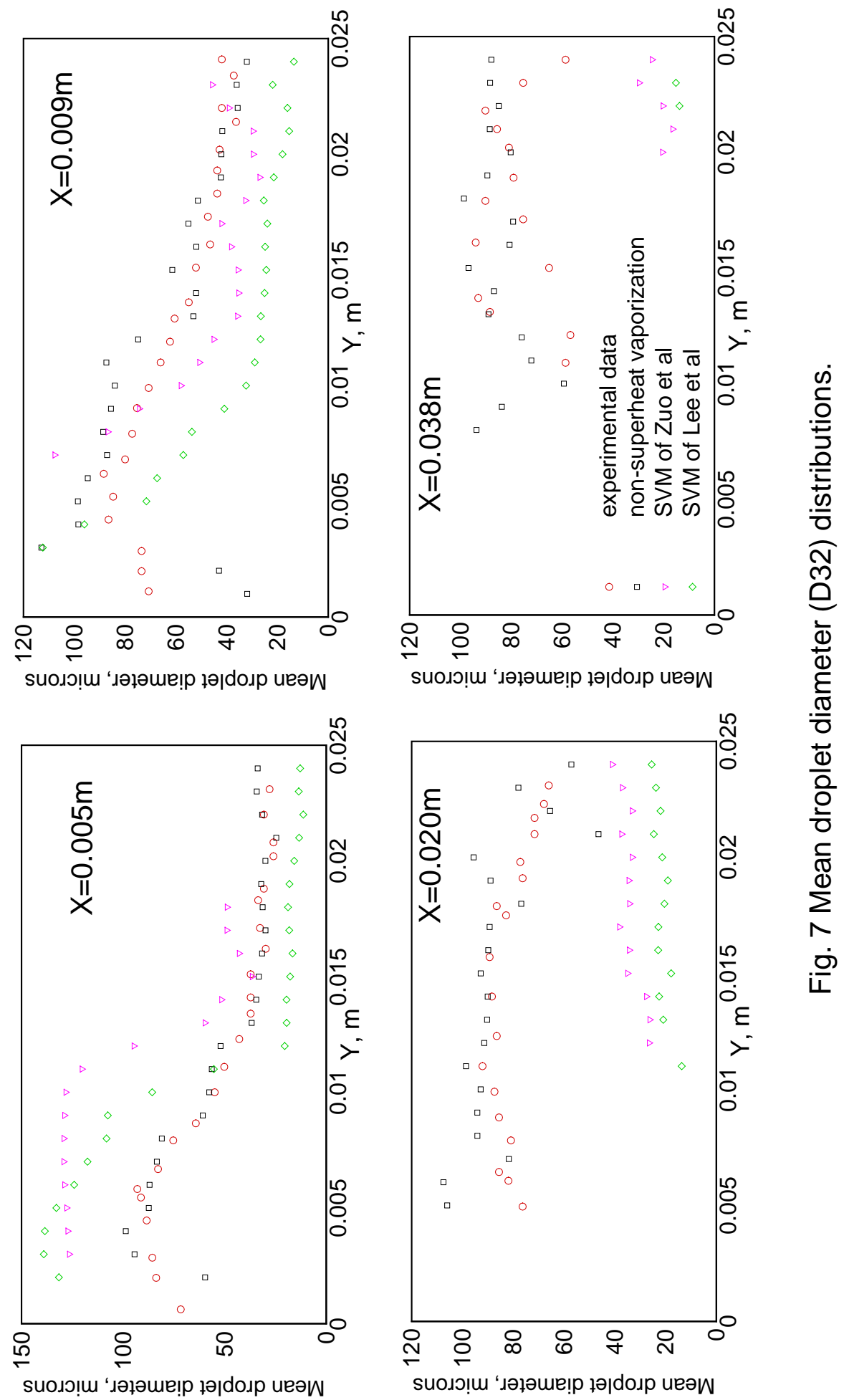

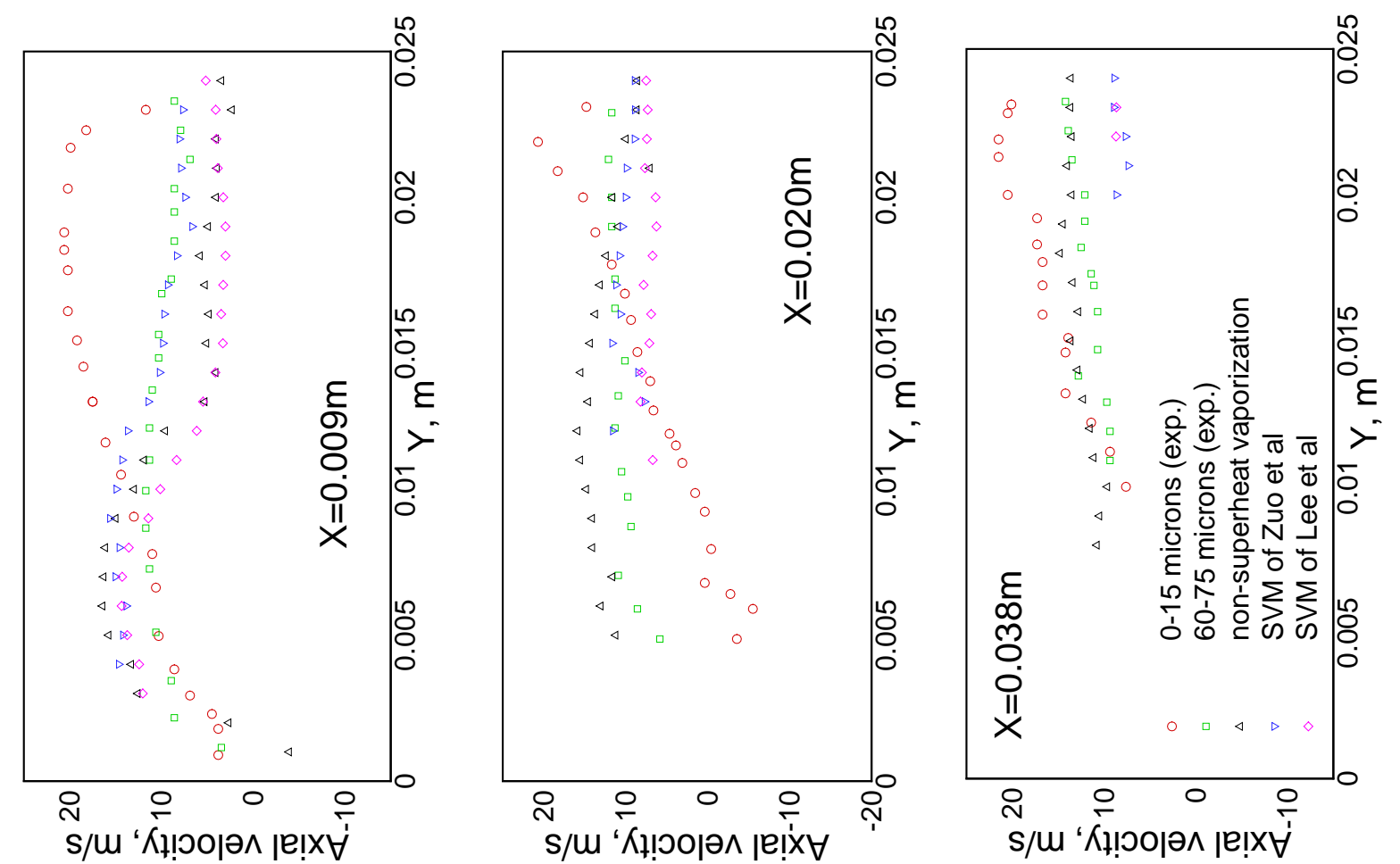

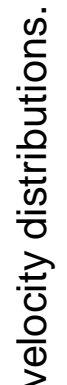
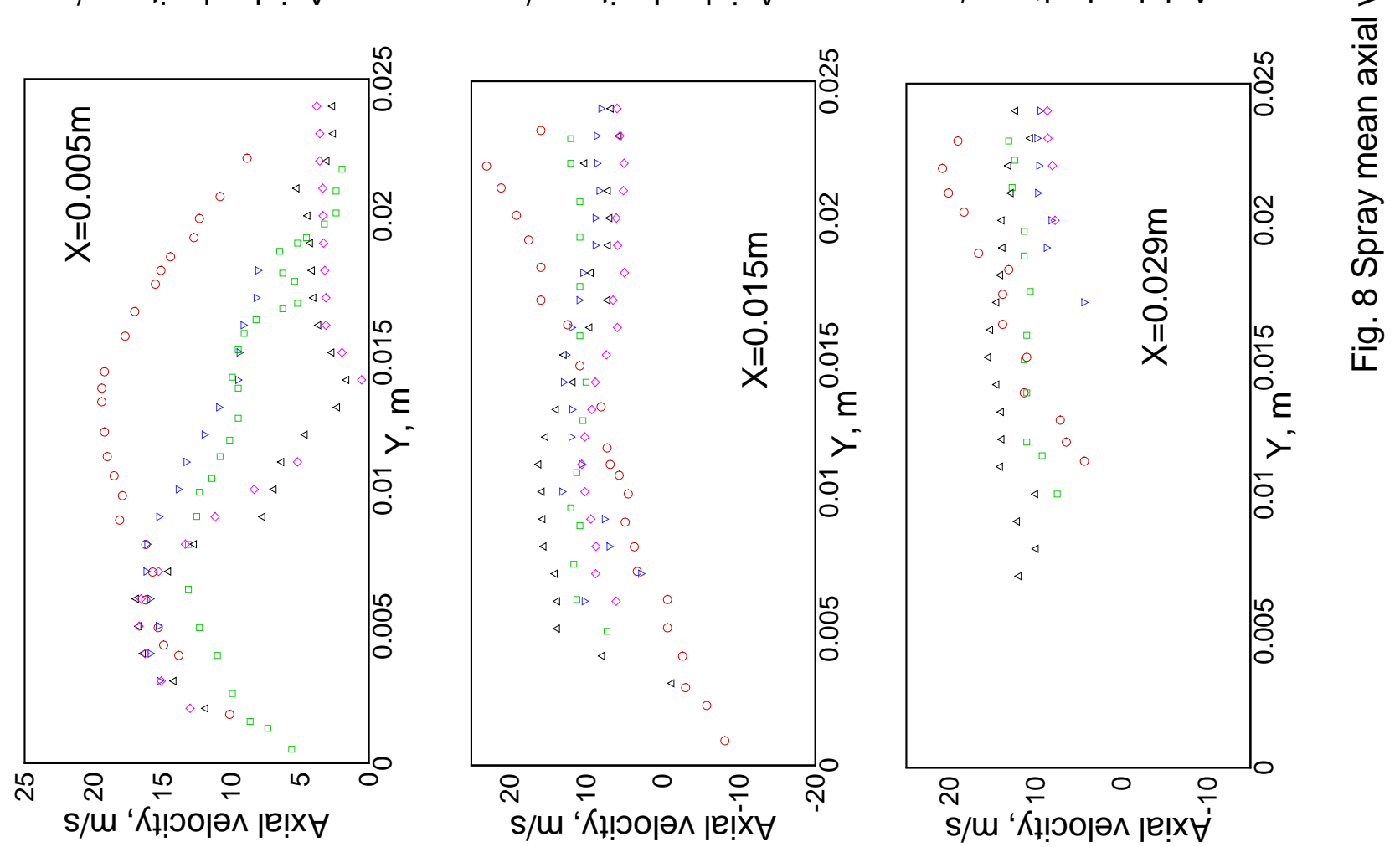

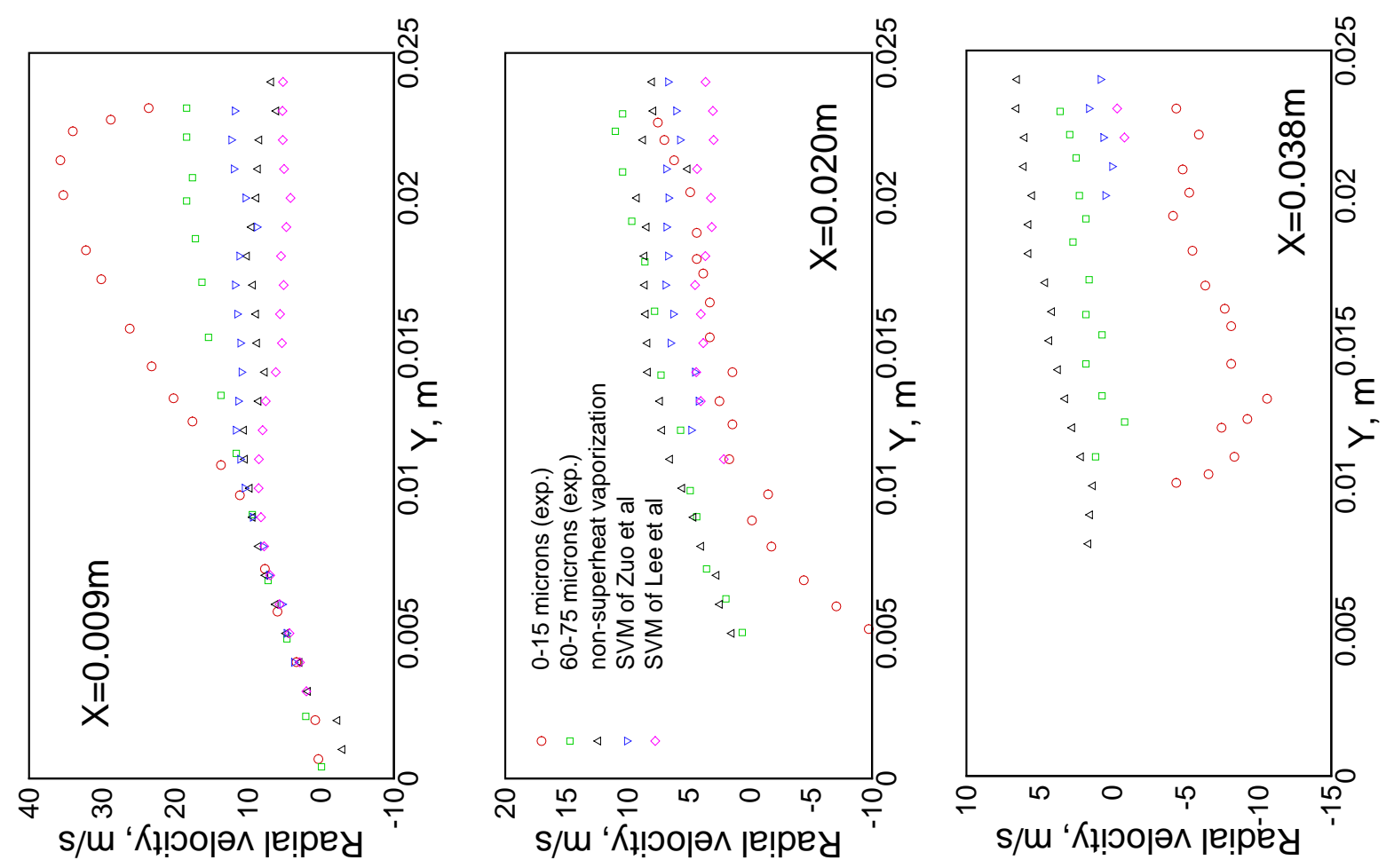

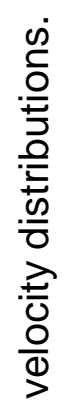
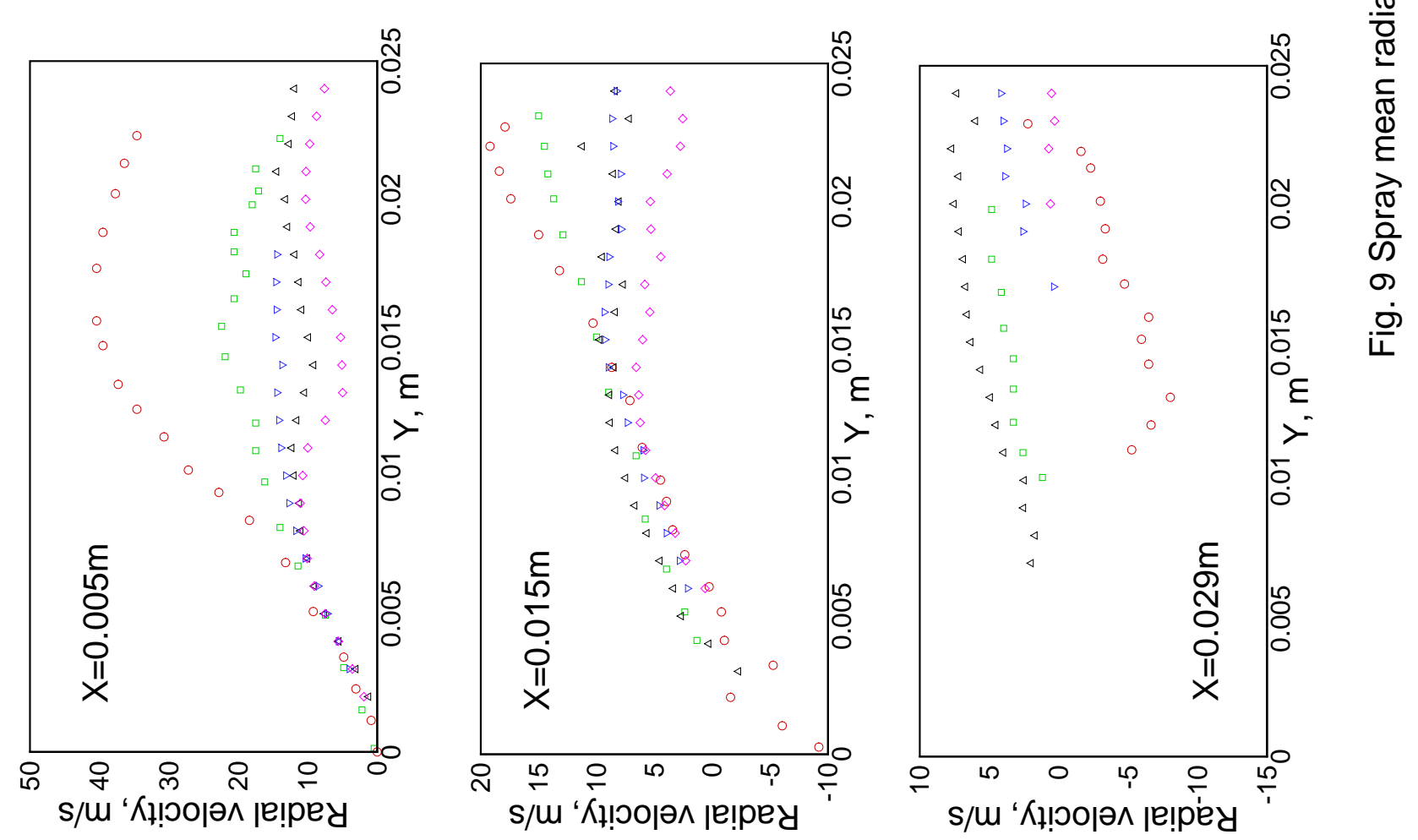

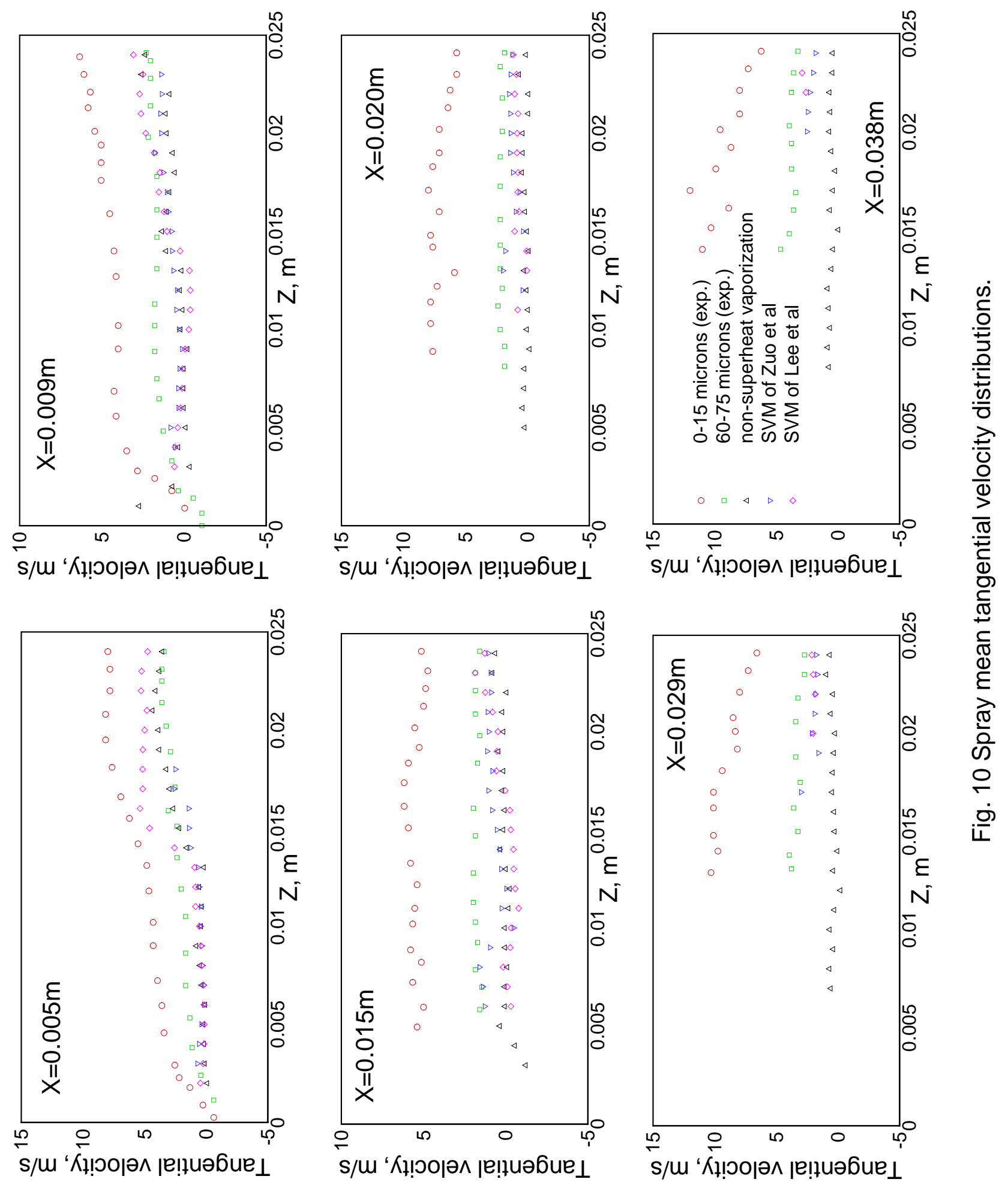


\begin{tabular}{|c|c|c|}
\hline \multicolumn{2}{|c|}{ REPORT DOCUMENTATION PAGE } & $\begin{array}{l}\text { Form Approved } \\
\text { OMB No. 0704-0188 }\end{array}$ \\
\hline \multicolumn{3}{|c|}{ 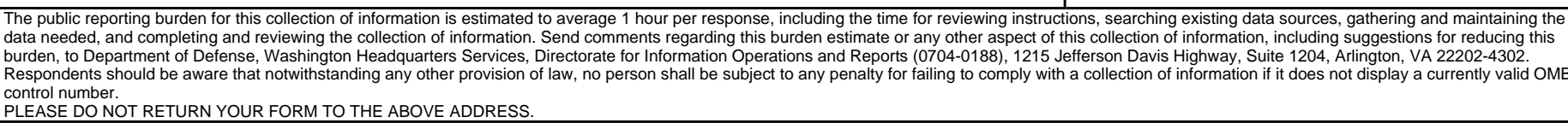 } \\
\hline $\begin{array}{l}\text { 1. REPORT DATE (DD-MM-YYYY) } \\
01-03-2012\end{array}$ & $\begin{array}{l}\text { 2. REPORT TYPE } \\
\text { Technical Memorandum }\end{array}$ & 3. DATES COVERED (From - To) \\
\hline \multirow{3}{*}{\multicolumn{2}{|c|}{$\begin{array}{l}\text { 4. TITLE AND SUBTITLE } \\
\text { Current Status of Superheat Spray Modeling With NCC }\end{array}$}} & 5a. CONTRACT NUMBER \\
\hline & & 5b. GRANT NUMBER \\
\hline & & 5c. PROGRAM ELEMENT NUMBER \\
\hline \multirow{3}{*}{\multicolumn{2}{|c|}{$\begin{array}{l}\text { 6. AUTHOR(S) } \\
\text { Raju, M., S.; Bulzan, Dan, L. }\end{array}$}} & 5d. PROJECT NUMBER \\
\hline & & 5e. TASK NUMBER \\
\hline & & $\begin{array}{l}\text { 5f. WORK UNIT NUMBER } \\
\text { WBS 984754.02.07.03.19.02 }\end{array}$ \\
\hline \multicolumn{2}{|c|}{$\begin{array}{l}\text { 7. PERFORMING ORGANIZATION NAME(S) AND ADDRESS(ES) } \\
\text { National Aeronautics and Space Administration } \\
\text { John H. Glenn Research Center at Lewis Field } \\
\text { Cleveland, Ohio 44135-3191 }\end{array}$} & $\begin{array}{l}\text { 8. PERFORMING ORGANIZATION } \\
\text { REPORT NUMBER } \\
\text { E-18044 }\end{array}$ \\
\hline \multirow{2}{*}{\multicolumn{2}{|c|}{$\begin{array}{l}\text { 9. SPONSORING/MONITORING AGENCY NAME(S) AND ADDRESS(ES) } \\
\text { National Aeronautics and Space Administration } \\
\text { Washington, DC 20546-0001 }\end{array}$}} & $\begin{array}{l}\text { 10. SPONSORING/MONITOR'S } \\
\text { ACRONYM(S) } \\
\text { NASA }\end{array}$ \\
\hline & & $\begin{array}{l}\text { 11. SPONSORING/MONITORING } \\
\text { REPORT NUMBER } \\
\text { NASA/TM-2012-217295 }\end{array}$ \\
\hline \multicolumn{3}{|c|}{$\begin{array}{l}\text { 12. DISTRIBUTION/AVAILABILITY STATEMENT } \\
\text { Unclassified-Unlimited } \\
\text { Subject Category: } 07 \\
\text { Available electronically at http://www.sti.nasa.gov } \\
\text { This publication is available from the NASA Center for AeroSpace Information, 443-757-5802 }\end{array}$} \\
\hline
\end{tabular}

\section{ABSTRACT}

An understanding of liquid fuel behavior at superheat conditions is identified to be a topic of importance in the design of modern supersonic engines. As a part of the NASA's supersonics project office initiative on high altitude emissions, we have undertaken an effort to assess the accuracy of various existing CFD models used in the modeling of superheated sprays. As a part of this investigation, we have completed the implementation of a modeling approach into the national combustion code (NCC), and then applied it to investigate the following three cases: (1) the validation of a flashing jet generated by the sudden release of pressurized R134A from a cylindrical nozzle, (2) the differences between two superheat vaporization models were studied based on both hot and cold flow calculations of a Parker-Hannifin pressure swirl atomizer, (3) the spray characteristics generated by a single-element LDI (Lean Direct Injector) experiment were studied to investigate the differences between superheat and non-superheat conditions. Further details can be found in the paper.

\section{SUBJECT TERMS}

Spray combustion; Atomization; Turbulent combustion; Superheat spray; CFD modeling

\begin{tabular}{|c|c|c|c|c|}
\hline \multicolumn{3}{|c|}{ 16. SECURITY CLASSIFICATION OF: } & \multirow{2}{*}{$\begin{array}{l}\text { 17. LIMITATION OF } \\
\text { ABSTRACT } \\
\text { UU }\end{array}$} & \multirow{2}{*}{$\begin{array}{l}\text { 18. NUMBER } \\
\text { OF } \\
\text { PAGES } \\
27\end{array}$} \\
\hline $\begin{array}{l}\text { a. REPORT } \\
U\end{array}$ & $\begin{array}{l}\text { b. ABSTRACT } \\
U\end{array}$ & $\begin{array}{l}\text { c. THIS } \\
\text { PAGE } \\
\text { U }\end{array}$ & & \\
\hline
\end{tabular}

19a. NAME OF RESPONSIBLE PERSON STI Help Desk (email:help@sti.nasa.gov) 19b. TELEPHONE NUMBER (include area code) 443-757-5802 
